\title{
Anti-shock Measures relieved Bee-Sting Anaphylaxis- Induced Kounis Type I Syndrome; A case Report
}

\author{
Yasser Mohammed Hassanain Elsayed* \\ Critical Care Unit, Fraskour Central Hospital, Damietta Health Affairs, Egyptian Ministry of Health (MOH), Egypt
}

*Corresponding author: Yasser Mohammed Hassanain Elsayed, Critical Care Unit, Fraskour Central Hospital, Damietta Health

Affairs, Egyptian Ministry of Health (MOH), Damietta, Egypt

\begin{abstract}
ARTICLE INFO
Received: 慧 November 06, 2019

Published: 幽 November 14, 2019

Citation: Yasser Mohammed Hassanain Elsayed. Anti-shock Measures relieved Bee-Sting Anaphylaxis-Induced Kounis Type I Syndrome; A case Report. Biomed J Sci \& Tech Res 22(5)-2019. BJSTR. MS.ID.003819.
\end{abstract}

Abbreviations: ABG: Arterial Blood Gas; BP: Blood Pressure; ACS: Acute Coronary Syndromes; CAD: Coronary Artery Disease; CAS: Coronary Artery Spasm; ECG: Electrocardiography; ICU: Intensive Care Unit; KS: Kounis Syndrome; PVCs: Premature Ventricular Contractions; VR: Ventricular Rate

\section{ABSTRACT}

Rationale: Anaphylaxis is a potentially life-threatening, systemic, allergic reaction that requires both immediate recognition and aggressive treatment. Acute coronary syndromes sometimes are allergic in origin that referred to Kounis syndrome. Coronary artery spasm and myocardial injury in the absence of evident preexistent coronary artery disease can occur in the setting of an urticarial reaction. $\urcorner$ The most frequent triggers of severe anaphylactic reactions are drugs, insect venoms, and foods. Anti- anaphylactic measures are established therapy for anaphylaxis but not for coronary artery disease.

Patient Concerns: The current case is a bee venom-induced anaphylactic shock with coronary vasospasm.

Diagnosis: Wasp sting anaphylaxis induced Kounis type I syndrome

Interventions: Electrocardiography, oxygenation, Intensive care monitoring, and arterial blood gas.

Outcomes: This case report describes the efficacy of anti-anaphylactic therapies with normalization of the electrocardiographic coronary artery spasm.

Lessons: This case report emphasizes both the importance of recognizing the main etiology of coronary vasospasm that was induced by anaphylaxis and manage it. The most interesting point in my case is a dramatic response of an electrocardiographic STsegment depression to anti-anaphylactic measures.

Keywords: Anti-Shock Measures; Bee Stings; Anaphylaxis; Kounis Type I Syndrome

\section{Introduction}

Allergic angina and allergic myocardial infarction (MI) are renowned as Kounis syndrome (KS) [1]. KS was initially described by Kounis and Zavras in 1991 [2-4]. Kounis syndrome is the synchronization of acute coronary syndromes (ACS) with mastcell and platelet activation in the setting of allergic or anaphylactic insults [5]. The pathogenesis of KS involves the production of inflammatory cytokines via mast cell stimulation which results in coronary artery spasm (CAS) rather than the atheromatous plaque, erosion, and rupture [3]. Histamine is the essential amine released chemical during allergic reactions that can provoke CAS manifested as angina pectoris [2]. Three variants of KS have been described. In the variant I (the most common variant, $72.6 \%$ ), the release of inflammatory mediators induces CAS with or without an increase of cardiac enzymes and troponins. In variant II (22.3\%), the release of inflammatory mediators induces CAS together with plaque erosion or rupture manifesting as acute MI. The variant III (5.1\%) includes patients with coronary artery stent thrombosis as a result of an allergic reaction. Patients with the type I variant may benefit from the treatment of the allergic reaction, which, by itself, can resolve the cardiac manifestation [6]. Anaphylaxis is an acute systemic reaction with symptoms of an immediate-type allergic reaction which is potentially life-threatening [7]. Anaphylactic shock is a surprising, sudden and sometimes deadly event that affects the patient in $75 \%$ of the cases without a pre-existent history of allergy [1]. Anaphylaxis is more favorable if any $\geq$ one of the following three criteria is accomplished: 
1. Acute onset of the illness (minutes to several hours) with the involvement of the skin, mucosal tissue, or both (e.g., hives; pruritus; flushing; swollen lips, tongue, uvula).

2. And $\geq$ one of the following: a. Respiratory compromise (e.g., dyspnea, wheezing or bronchospasm, stridor, reduced peak flows, hypoxia). b. Reduced blood pressure or associated symptoms of end-organ dysfunction (e.g., syncope, incontinence)

3. $\geq$ Two of the following that occurs rapidly after exposure to a likely allergen for that patient (minutes to several hours):

a. Involvement of the skin or mucosal tissue (e.g., hives; itching; flushing; swollen lips; tongue; uvula).

b. Respiratory compromise

c. Decreased blood pressure (BP) or associated symptoms. $\mathrm{d}$. Persistent gastrointestinal symptoms (e.g., crampy abdominal pain, vomiting).

4. Decreased BP after allergen exposure (minutes to several hours)

a. Infants and children: low systolic BP (dependent on age) or $>30 \%$ decrease in systolic BP. b. Adults: systolic BP of less than $90 \mathrm{mmHg}$ or greater than $30 \%$ decrease from that person's baseline [8].

The commonest inducers for severe anaphylactic reactions are drugs, insect venoms, and foods [7]. It is well-known that anaphylaxis causes systemic vasodilation and reduced venous return due to raised vascular permeability and therefore may result in a depressed cardiac output, resulting in coronary hypoperfusion and cardiac damage [4]. Serious allergic reactions may be the cause

\section{Case Presentation}

Figure 1:

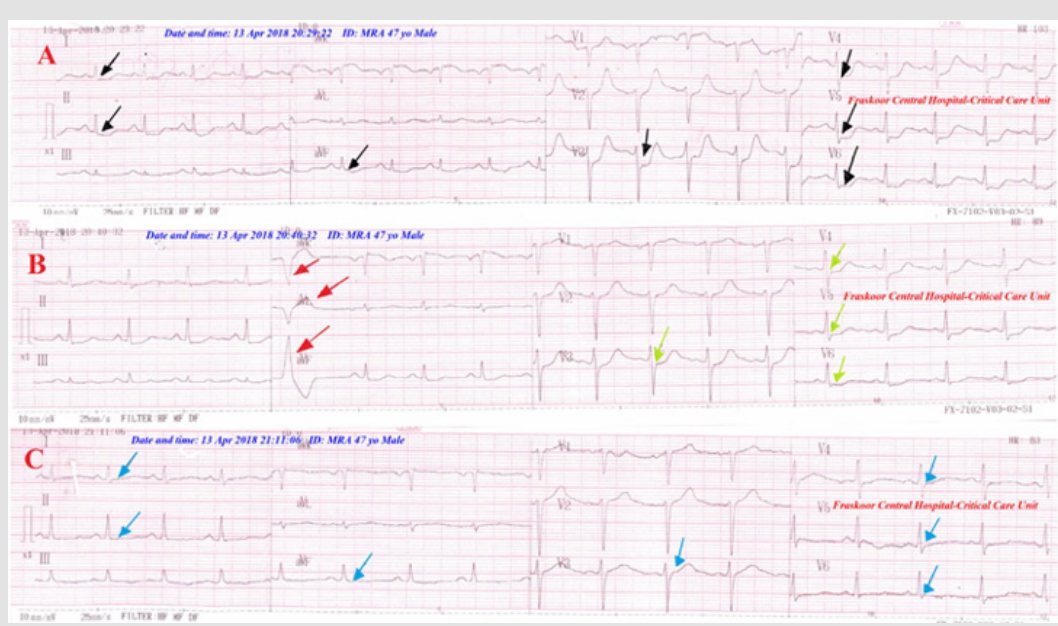

A. Serial ECG tracings; A. tracing; the initial emergency ECG showing significant straight ST-segment depressions in I, aVL, II, aVF, and V3-6 ECG leads (black arrows).

B. tracing; the $2^{\text {nd }}$ ECG tracing was taken within 10 minutes of starting therapy showing partial decreasing of previous STsegment depressions (lemon arrows) with sporadic premature ventricular contractions in aVR, aVL, and aVF (red arrows).

C. tracing; the $2^{\text {nd }}$ ECG tracing was taken within 40 minutes of starting therapy and $1^{\text {st }}$ ECG tracing doing 10 minutes of starting therapy showing complete ECG and ST-segment depression normalization (blue arrows).

Copyright@ Yasser Mohammed Hassanain Elsayed | Biomed J Sci \& Tech Res | BJSTR. MS.ID.003819. 
A 47-year-old married, carpenter, Egyptian male, was admitted to the intensive care unit (ICU) with anaphylactic shock, acute pulmonary edema, and coronary artery spasm. The relatives had given a recent history of patient therapeutic exposure to multiple bee stings at both temporal head areas. The patient tried to the management of headache with bee stings. The relatives also added a history of pre-hospital IV injection of $80 \mathrm{mg}$ furosemide for acute pulmonary edema. The patient started complaining of acute chest pain, the difficulty of breathing, and sudden loss of consciousness within about 20 minutes of stings. On examination, the patient was unconscious and facial swelling with local stings effects was seen on temporal head areas. Frothy mouth, angioedema, and generalized urticarial rash but with no central cyanosis were noted. His vital signs were as follows: $\mathrm{BP}$ of $80 / 60 \mathrm{mmHg}$, the pulse rate of 100 $\mathrm{b} /$ minute, RR of $38 \mathrm{~b} /$ minute and the temperature of $37.6^{\circ} \mathrm{C}$. Generalized coarse crackles and scattered wheezing were heard without auscultation which confirmed on chest examination. No more relevant other clinical data. The initial ECG tracing was taken just before medications showed; sinus tachycardia with straight ST-segment depression in I, aVL, II, aVF, V3-6 ECG leads (Figure 1A). The second ECG tracing showed a gradual resolution of ST-segment depression with few premature ventricular contractions (Figure 1B).

The third ECG tracing showed normalization of ST-segment (Figure 1C) The major differential diagnosis of Kounis syndrome is Takotsubo or stress-induced cardiomyopathy. But the differential diagnosis of anaphylaxis maybe including vasovagal syncope, cardiogenic shock, cardiac arrhythmia, pulmonary embolism, hyperventilation syndrome, epilepsy, coma, status asthmaticus, acute tracheal/bronchial obstruction, urticaria and hereditary/ acquired angioedema, and toxic substances eg., ethanol, scombroid poisoning, morphine, and Hoigné-syndrome. The patient workup was: ABG and electrolytes profile (Figure-2) were done within 20 minutes of admission and start of therapy that showing: hyponatremia; $\mathrm{Na}+:$ 129mmol/l, K+: $4.6 \mathrm{mmol} / \mathrm{L}$, ICa++: $1.05 \mathrm{mmol} / \mathrm{L}$ and slight hypoxia. His hemogram was unremarkable except for marked anemia; Hb:7.3 gm/dl, RBCs: $2.41 \mathrm{~m} / \mathrm{L}$. Normal liver and kidney function; SGPT: 7 U/L, SGOT: 9 U/L, and serum creatinin: $0.9 \mathrm{mg} / \mathrm{dl}$. Both CPK-MB and troponin levels were normal. Random blood glucose: $229 \mathrm{mg} / \mathrm{dl}$. Echocardiography showed an absence of any hypokinetic abnormalities with a normal ejection fraction ( EF:72\%). The patient was managed urgently in the intensive care unit with high flow 100\% 02 inhalation, IM adrenaline ampoule; $1 \mathrm{mg}$ of 1:1000, IV hydrocortisone $200 \mathrm{mg}$, IV chlorpheniramine maleate $10 \mathrm{mg}$, IV dexamethasone $8 \mathrm{mg}$, normal saline $0.9 \% 500 \mathrm{ml}$, and Ringer solution $500 \mathrm{ml}$. Dramatic response of anaphylaxis to anti-anaphylactic measures with clinical and electrocardiographic ST-segment depression improvement had happened. Standard anti-ischemic drugs were not given. A complete recovery was achieved.

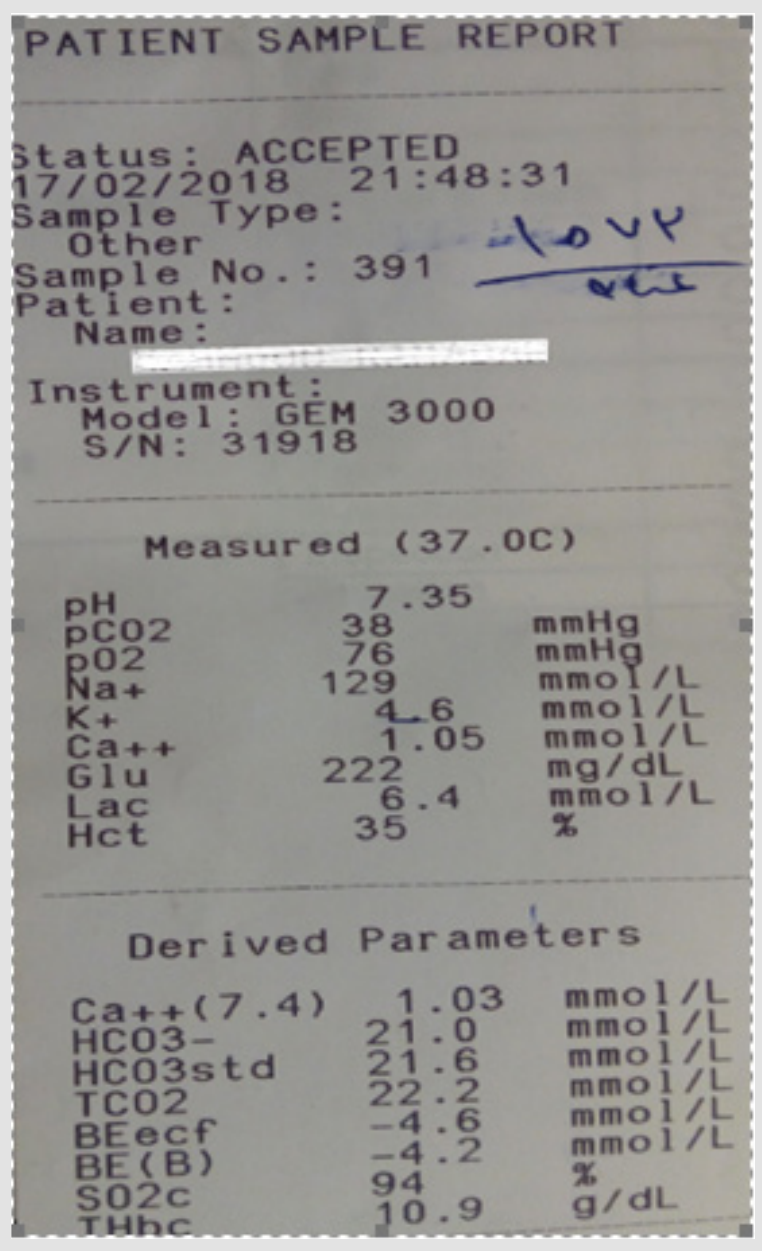

Figure 2: $A B G$ and electrolytes profile on the recovery stage are showing hyponatremia and slight hypoxia.

\section{Discussion}

\section{Overview}

a. My case study was A 47-year-old male presented with anaphylactic shock, acute pulmonary edema, and coronary artery spasm after the patient therapeutic exposure to multiple bee stings at both temporal head areas.

b. I can't compare the current case with similar conditions. There are no similar or known cases with the same management for near comparison.

c. Study question here: How did the dramatic response happened in the case of allergic coronary artery vasospasm or Kounis type I syndrome after anti-shock measures?

d. The primary objective for my case study was the presence of anaphylactic shock, acute pulmonary edema, and coronary artery spasm after patient therapeutic exposure to multiple bee stings. 
e. The secondary objective for my case study was the clinical improvement rather than the normalization of typical STsegment depressions as was seen in the serial ECG tracings that indicate the presence of coronary artery vasospasm.

\section{Limitations of the study}

There are no known limitations in the study.

\section{Recommendations}

It is recommended to widening the research in clearing the effect of anti-shock measures in anaphylaxis on allergic coronary artery vasospasm or Kounis type I syndrome

\section{Conclusion}

Dramatic improvement of allergic coronary artery vasospasm or Kounis type I syndrome with anti-shock measures without using ani-ischemic heart disease medications. Physician priority in the management should be directed to the etiology. It may be vital and critical. The physician managed the case as anaphylaxis, not as coronary artery vasospasm but the anti-shock therapies improved both.

\section{Conflicts of Interest}

There are no conflicts of interest.

\section{Acknowledgment}

I wish to thank critical care unit nurses who make extra ECG copies for helping me. I wish to thank Dr. Osama Maria, MD Ph.D. who edited the manuscript, and my professor Dr. Mohamed Khashaba, Ph.D., MD, for his encouragement in conducting my researches.

\section{ISSN: 2574-1241}

DOI: 10.26717/BJSTR.2019.22.003819

Yasser Mohammed Hassanain Elsayed. Biomed J Sci \& Tech Res

This work is licensed under Creative Commons Attribution 4.0 License

Submission Link: https://biomedres.us/submit-manuscript.php

\section{References}

1. Rayamane AP, Kumar MP, Kishor DG, Dayananda RAS (2014) Honeybee sting and anaphylaxis: Review. Journal of Forensic Medicine, Science and Law 23(1): 1-7.

2. Kounis NG, Zavras GM (1991) Histamine-induced coronary artery spasm: the concept of allergic angina. Br J Clin Pract 45(2): 121-128.

3. Kounis NG (2006) Kounis syndrome (allergic angina and allergic myocardial infarction): a natural paradigm? Int J Cardiol 110(1): 7-14.

4. Memon S, Chhabra L, Masrur S, Parker MW (2015) Allergic acute coronary syndrome (Kounis syndrome). Proc (Bayl Univ Med Cent) 28(3): 358-362.

5. Kounis NG (2016) Kounis syndrome: An update on epidemiology, pathogenesis, diagnosis and therapeutic management, Clin. Chem. Lab. Med 54(10): 1545-1559.

6. Abdelghany M, Subedi R, Shah S, Kozman H (2017) Kounis syndrome: A review article on epidemiology, diagnostic findings, management and complications of allergic acute coronary syndrome. International Journal of Cardiology 232: 1-4.

7. Ring J, Beyer K, Biedermann T, Andreas Bircher, Dorothea Duda, et al. (2014) Guideline for acute therapy and management of anaphylaxis. Allergo J Int 23(3): 96-112.

8. Jacobsen RC, Gratton MC (2011) A case of unrecognized prehospital anaphylactic shock. Prehosp Emerg Care 15(1): 61-66.

9. Anandan PK, Hanumanthappa NB, Bhatt P, Cholenahally MN (2015) Allergic angina following wasp sting: Kounis syndrome, Case Report. Oxford Medical Case Reports 6: 306-308.

10. Gupta MK, Gupta P, Rezai F (2001) Histamine can it cause an acute coronary event?-Short Communications. Clin Cardiol 24(3): 258-259.

11. Ewan PW (1985) Allergy to insect stings: a review. Journal of the Royal Society of Medicine 78(3): 234-239.

12. Riches KJ, Gillis D, James RA (2002) An autopsy approach to bee stingrelated deaths. Pathology 34(3): 257-262.

13. Kemp SF, Lockey RF, Simons FE (2008) Epinephrine: the drug of choice for anaphylaxis. Allergy 63(8): 1061-1070.

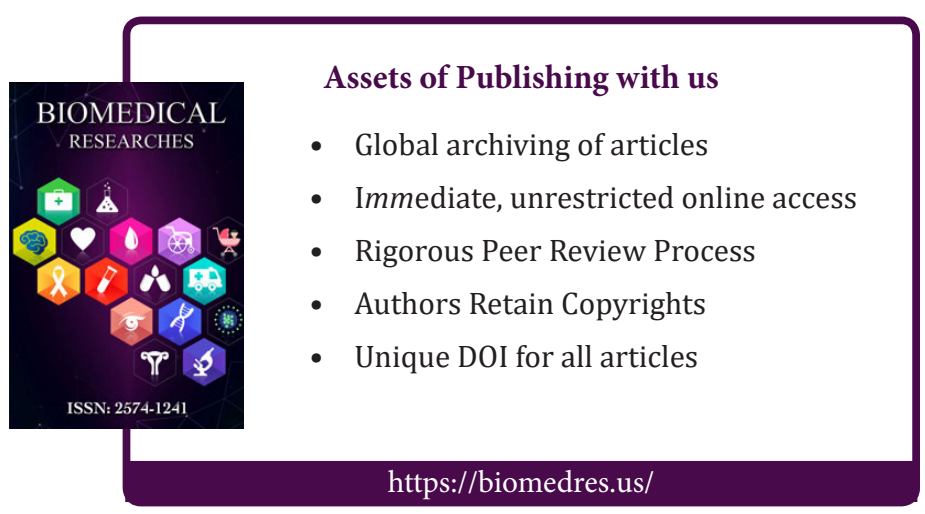

